Canadian Journal of Higher Education Revue canadienne d'enseignement supérieur

Volume 48, No. 3, 2018, pages $141-164$

\title{
Stressing in the Fall: Effects of a Fall Break on Undergraduate Students
}

Heather Poole

University of Ottawa

Ayesha Khan

McMaster University

Michael Agnew

McMaster University

\begin{abstract}
Universities across Canada are responding to increasing levels of student stress and mental illness by introducing a fall break. However, scant research has investigated the effectiveness of this intervention. Our team assessed perceived stress and the number of stressors experienced by students at McMaster University using established self-report stress questionnaires, comparing stress before and after the break. We found that despite the widespread expectation that a fall break will decrease student stress, the effects of this intervention are not straightforward. Students experienced fewer stressors after the break than before it, but experienced higher levels of overall stress. Additionally, stress varied according to several demographic variables, revealing some groups to be at higher risk for stress-related problems. Given the widescale adoption of fall breaks, we hope that this investigation can initiate dialogue about the importance of evidence-based decisions in the development of stress-reduction interventions for Canadian university students.
\end{abstract}

\section{Résumé}

Des niveaux de stress et de maladie mentale croissent chez les étudiants. En réaction, les universités Canadiennes introduisent une pause d'étude à l'automne. Cependant, peu de recherches ont étudié l'efficacité de cette intervention. Notre équipe avait utilisé des questionnaires de stress pour évaluer le stress vécus par les étudiants de McMaster University, en comparant le stress avant et après la pause d'étude à l'automne. Malgré les attentes 
généralisées qu'une pause à l'automne diminue le stress des étudiants, les effets de cette intervention ne sont pas simples. Les étudiants ont connu moins de facteurs de stress après la pause qu'avant, mais ont éprouvé des niveaux plus élevés de stress global. Compte tenu de l'adoption à grande échelle des pauses d'étude d'automne, nous espérons que cette recherche peut initier un dialogue sur l'importance des décisions fondées sur des preuves dans le développement d'interventions de réduction du stress pour les étudiants universitaires Canadiens.

\section{Introduction}

The topic of mental health and wellness of university and college students has been receiving increasing attention, as popular media coverage and empirical research have indicated that post-secondary students are reporting remarkably high levels of stress and instances of mental illness (Adlaf, Gliksman, Demers, \& Newton-Taylor, 2001; Casey, 2017; Chiose, 2016; Durand-Bush, McNeil, Harding, \& Dobransky, 2015; Ibrahim, Kelly, Adams, \& Glazebrook, 2013; Kitzrow, 2003; Lewin, 2011; Lunau, 2012; Scelfo, 2016; Smith, 2016; Stallman, 2010; Warner, 2016). In 2016, the American College Health Association released a report based on the largest known comprehensive survey on the health of post-secondary students, the National College Health Assessment. Over 43,000 students across 41 Canadian post-secondary institutions were surveyed, and the report revealed that Canadian students are in a state of crisis. A total of $59.6 \%$ of respondents reported feeling hopeless at some point within the last 12 months, $89.5 \%$ felt overwhelmed, 88.2\% felt exhausted, $64.5 \%$ felt overwhelming anxiety, and $13 \%$ had seriously considered suicide. Students also reported that the top four factors negatively influencing their academic performance were stress (42.2\%), anxiety (32.5\%), sleep difficulties (28.4\%), and depression (20.9\%) (American College Health Association, 2016). Though alarming, these results are in line with other findings about student mental health, since this group traditionally reports higher stress than that of the general population (Adlaf et al., 2001; Ibrahim et al., 2013; Stallman, 2010), and their levels of anxiety and stress have risen in recent years (Booth, Sharma, \& Leader, 2016).

Indeed, the mental health and wellness of post-secondary students is of particular concern given that the onset of mental illness commonly occurs between the ages of 15 and 24 (Eisenberg, Gollust, Golberstein, \& Hefner, 2007; Rao, Hammen, \& Daley, 1999), and that the stressors affecting their mental health may be different than their non-student counterparts or others in a different life stage. Stressors can vary greatly: the biological concept of stress defines a stressor as "anything that throws the body out of homeostatic balance-for example an injury, an illness, subjection to great heat and cold" (Sapolsky, 1994, p. 7). Stressors observed in students are unique since they are most often related to situational and time-based pressures that exist during short but intensive intervals (i.e., each academic term). Student-specific stressors may include adjusting to the transition into adulthood (Arnett, 1994), living independently and/or being homesick (Poyrazli \& Lopez, 2007), dealing with increases in academic workload (Archer \& Lamnin, 1985), and multiple and time-sensitive activities such as studying for different exams while completing assignments and lab work (Archer \& Lamnin, 1985). There could also be issues with adjusting to changing personal and professional relationships (Aherne, 2001), new financial pressures (Aherne, 2001; Archer \& Lamnin, 1985), changes in dietary habits (De- 
liens, Clarys, De Bourdeaudhuij, \& Deforche, 2014), and sleeping patterns (Lund, Reider, Whiting, \& Prichard, 2010), as well as handling social relationships and risky behaviours (Gerdes \& Mallinckrodt, 1994), extracurricular activities (Stuart, Lido, Morgan, Solomon, \& May, 2011), and family issues (Holahan, Valentiner, \& Moos, 1994). Accordingly, the documentation and assessment of the experience of stress and the effect of stressors on college and university students is a topic of interest for many researchers (Archer \& Lamnin, 1985; Beiter et al., 2015; Dill \& Henley, 1998; Hurst, Baranik, \& Daniel, 2013).

It is not surprising to note that there is an established relationship between student stress and poor health behaviours and outcomes. For example, undergraduate students who self-report high stress consume a greater amount of unhealthy foods and exercise less than those who do not self-report high stress (Hudd et al., 2000). Students who experience high levels of worry, stress, or anxiety also sleep less than their lower-stress counterparts (Ginsberg \& Gapen, 2007; Hicks \& Garcia, 1987; Hudd et al., 2000; Kelly, Kelly, \& Clanton, 2001); this is a concern since disturbances in sleep affect the body's response system through modulation of the metabolic and stress hormone cortisol (Loss, 1997). A study on nursing students showed that high stress levels were correlated with poor physical health and psychological distress (Klainin-Yobas et al., 2014). Subjective perceptions of examination stress in female students were associated with increased levels of leptin (Haleem, Haider, Perveen, \& Haleem, 2015), which is an important hormone in the maintenance of various bodily functions including energy balance (Elmquist, Bjorbaek, Ahiman, Flier, \& Saper, 1998) as well as mood and mental health (Jow, Yang, \& Chen, 2006).

Strategies to reduce stress and increase support for mental health among students are now commonplace across most institutions in Canada. For example, McMaster University's COPE program is designed to inform students about mental health while creating an atmosphere that encourages dialogue on the issue (COPE McMaster, n.d.). The University of British Columbia has a "Healthy Minds Project" that encompasses many initiatives, including regular blog posts about mental health awareness and overall well-being (Healthy Minds at UBC, n.d.). Recently, that university has created an undergraduate course (HEAL 100: Introduction and Principles of Health and Wellbeing) on the topic of mental health and well-being as it relates to issues specific to university students, such as academic success (University of British Columbia, 2017).

Many universities are training staff and faculty to meet the needs of students. For example, University of Guelph provides online modules that teach about mental health (Canadian Mental Health Association, n.d.), University of Manitoba provides a two-day workshop to help faculty and staff recognize and respond to young people struggling with mental health (University of Manitoba, 2014), and Queen's University circulates a brief document with guidelines for staff to identify and respond to students experiencing mental distress (Queen's Gazette, 2017). On a broader scale, Jack.org (JACK.org, n.d.) is a national organization that aims to decrease stigma and normalize conversations about mental health among young Canadians. In 2014, the Canadian Alliance for Student Associations released a policy paper requesting federal government intervention to create a mental health policy with a focus on post-secondary students (Bartlett, 2014), and in 2017 the Ontario Undergraduate Student Alliance declared that mental health of post-secondary students is now a major priority for student organizations across Canada (Canadian Alliance of Student Associations, 2017; OUSA, 2017). The Government of Ontario has funded the Centre for In- 
novation in Campus Mental Health (n.d.), providing support services for students including an anonymous, confidential, and free helpline for students in crisis (Good2Talk, n.d.).

Following a year in which several students died by suicide, Queen's University developed a task force to advise on the development of on-campus support resources for student mental health; the inclusion of a fall break was one recommendation stemming from that report (Walker, Tierney, Clapham, Medves, \& Jahchan, 2012). In October of 2015, a full-week fall break was introduced at McMaster University, in order to provide "students with a meaningful reprieve during a strategic moment in the course of their studies to improve academic performance and mental health and well-being" (McMaster Daily News, 2015). Likewise, across Canada, one of the most recent and consistent university interventions to support student mental health has been the introduction of a fall break, often with the rationale of reducing student stress, promoting overall mental health, and increasing retention and general academic success (Irish, 2013; Kirnishni, 2014). While a week-long winter break in February is a common and long-standing practice, the trend toward the adoption of a second break during the fall term has accelerated at institutions across Canada. We recently searched websites from 70 Canadian universities and found that 52 institutions had some form of a multi-day break in the 2017 fall term, and one school plans to add a fall break in 2018. Although several schools have reported internal evaluations of the students' perceptions of a fall break (e.g., Pilato, 2014; University of Waterloo, n.d.), there is very little peer-reviewed research on the topic (although see Cramer \& Pschibul, 2017; Poole, Khan, \& Agnew, 2017). Given the wide-scale adoption of fall breaks, it is now imperative to investigate whether implementation of such a break does in fact improve the mental health of students. This investigation can help inform the development of effective and evidence-based policy.

Our study was designed to address a gap in the literature about the efficacy of a fall break on the mental health of post-secondary students with the aim to investigate one important component of mental health: student stress. Using established and validated selfreport stress surveys (see Cohen, Kamarck, \& Mermelstein, 1983; Crandall, Preisler, \& Aussprung, 1992) we assessed overall perceived stress and the number of stressors from undergraduate students at McMaster University in Hamilton, Ontario. We investigated whether student stress would be different after a week-long fall break, in comparison to pre-break levels. During the subsequent winter term, we administered a follow-up survey to document student perceptions of the fall break on their entire fall term experience.

\section{Methods}

\section{Recruitment}

We advertised the study extensively on campus, using posters and in-class announcements. Additionally, we emailed all undergraduates currently registered at McMaster University $(N=24,473)$, with a link to an online survey. Students were emailed twice before the fall break in October 2015 (when the survey opened one week before the fall break, and three days later with a reminder email). Immediately after the fall break, all undergraduate students were again emailed and asked to complete a follow-up survey. Ethical guidelines stipulated that students could not be required to complete either survey, but we attempted to increase repeat responders by offering one entry into a prize draw upon participation in each survey. Although students were not required to have 
completed the first survey to complete the second one, we did link the responses of those that completed both the pre- and post-fall break surveys, using an anonymous unique ID code generated by respondents. Our surveys were designed so that students could skip any questions that they wished to.

\section{Surveys}

The surveys were hosted online via the open source web application LimeSurvey, endorsed by our university's Research Ethics Board. Students accessed them directly by clicking on the link in the email; access was only possible for the week following each initial email. After providing consent for the online survey, students were asked a series of demographic questions pertaining to their academic status and several personal characteristics (e.g., faculty, year of study, sleep habits). The personal characteristics were chosen to allow us to identify differences in stress levels between different groups, and the behavioural characteristics were chosen due to their documented links to stress.

Additionally, the online surveys comprised two validated and standardized measures of stress. The Undergraduate Stress Questionnaire (USQ; Crandall et al., 1992) is a scale that was developed to assess stress in undergraduate students, out of consideration that this population experiences a unique set of school-related stressors that may not be identified using adult-normed measures of stress. Students indicate which life event stressors (out of 83) they have experienced in the past two weeks. Some examples of stressors listed on this measure include lack of money, had a lot of tests, no sleep, had a hangover, and felt isolated. The USQ has good reliability (test-retest reliability: $r=0.59$, split-half reliability = 0.71, internal consistency: $K R-21=0.81$; Crandall et al., 1992). Validity has also been established: USQ scores increase with self-reported stress and correlate with other measures of stress (see Crandall et al., 1992, for details). The questionnaire typically takes three to five minutes to complete.

One criticism of the USQ is that it does not provide subjective ratings of the stressfulness of each experienced life event. Since different individuals respond differently to stressors, our survey also included the Perceived Stress Scale (PSS; Cohen et al., 1983). This is a scale with Canadian norms that assesses the degree to which an individual views their life to be stressful. The scale has 10 items that measure how frequently in the last month respondents have experienced various thoughts and feelings related to stress. Items are scored using a 5-point scale from "never" to "very often." Seven items are reverse scored. The PSS has good reliability and validity (see Cohen et al., 1983, for details). Norms for undergraduate students are approximately 13, with some variability due to gender and race (Cohen et al., 1983).

\section{January Survey}

In the second week of the winter 2016 term, we again emailed all undergraduate students with a request to complete a brief survey assessing the effect of the fall break on their stress levels and academic performance over the entire fall semester. This survey was designed to provide a comprehensive self-assessment of the effect of the fall break, accounting for its influence on the experience of the final exam period in December 2015. We also included a global question asking students whether they found the fall break to be a good thing for them. As before, students received a reminder email three days after the initial email. 
This study was approved by the McMaster University Research Ethics Board, in compliance with Canada's Tri-Council Policy Statement on the ethical conduct for research involving humans.

\section{Results}

\section{Sample Characteristics}

All undergraduate students at McMaster University $(N=24,473)$ were contacted by email with the request to complete our surveys. Of those contacted, 997 completed the pre-break survey, 1,444 completed the post-break survey, and 1,146 completed the January survey. Demographic data for the two main surveys are reported in Table 1.

Table 1. Demographic data of respondents on pre-break and post-break surveys

\begin{tabular}{|c|c|c|c|c|c|c|}
\hline \multirow[t]{2}{*}{$\begin{array}{l}\text { Demographic } \\
\text { characteristic }\end{array}$} & & & \multicolumn{2}{|c|}{$\begin{array}{l}\text { Pre-break } \\
\text { respondents }\end{array}$} & \multicolumn{2}{|c|}{$\begin{array}{l}\text { Post-break } \\
\text { respondents }\end{array}$} \\
\hline & & & $\mathrm{N}$ & $\%$ & $\mathrm{~N}$ & $\%$ \\
\hline \multirow[t]{4}{*}{ Gender } & Total & & 987 & & 1316 & \\
\hline & & Male & 269 & 27.25 & 322 & 24.47 \\
\hline & & Female & 713 & 72.24 & 987 & 75.00 \\
\hline & & Transgender & 5 & 0.51 & 7 & 0.53 \\
\hline \multirow[t]{3}{*}{ First generation } & Total & & 997 & & 1444 & \\
\hline & & Yes & 751 & 75.33 & 300 & 20.78 \\
\hline & & No/Unsure & 246 & 24.67 & 1144 & 79.22 \\
\hline \multirow[t]{3}{*}{ Type of enrollment } & Total & & 991 & & 1324 & \\
\hline & & Full-time & 951 & 95.96 & 1271 & 96.00 \\
\hline & & Part-time & 37 & 3.73 & 51 & 3.85 \\
\hline \multirow[t]{6}{*}{ Year of study } & Total & & 995 & & 1323 & \\
\hline & & First & 45 & 4.52 & 58 & 4.38 \\
\hline & & Second & 250 & 25.13 & 407 & 30.76 \\
\hline & & Third & 298 & 29.95 & 424 & 32.05 \\
\hline & & Fourth & 350 & 35.18 & 362 & 27.36 \\
\hline & & Fifth & 45 & 4.52 & 63 & 4.76 \\
\hline \multirow[t]{7}{*}{ Faculty } & Total & & 977 & & 1316 & \\
\hline & & Health Sciences & 175 & 17.91 & 207 & $15 \cdot 73$ \\
\hline & & Engineering & 193 & 19.75 & 228 & 17.33 \\
\hline & & Social Sciences & 185 & 18.94 & 199 & 15.12 \\
\hline & & Science & 254 & 26.00 & 396 & 30.09 \\
\hline & & Business & 59 & 6.04 & 78 & 5.93 \\
\hline & & Humanities & 111 & 11.36 & 172 & 13.07 \\
\hline
\end{tabular}




\begin{tabular}{|c|c|c|c|c|c|c|}
\hline \multirow[t]{2}{*}{$\begin{array}{l}\text { Demographic } \\
\text { characteristic }\end{array}$} & & & \multicolumn{2}{|c|}{$\begin{array}{l}\text { Pre-break } \\
\text { respondents }\end{array}$} & \multicolumn{2}{|c|}{$\begin{array}{l}\text { Post-break } \\
\text { respondents }\end{array}$} \\
\hline & & & $\mathrm{N}$ & $\%$ & $\mathrm{~N}$ & $\%$ \\
\hline \multirow[t]{5}{*}{ University GPA } & Total & & 934 & & 1261 & \\
\hline & & $0-4$ & 19 & 2.03 & 29 & 2.30 \\
\hline & & $5-7$ & 225 & 24.09 & 325 & 25.77 \\
\hline & & $8-10$ & 515 & 55.14 & 679 & 53.85 \\
\hline & & $11-12$ & 175 & 18.74 & 228 & 18.08 \\
\hline \multirow[t]{3}{*}{ Gets enough sleep } & Total & & 996 & & 1317 & \\
\hline & & Yes & 418 & 41.97 & 467 & 35.46 \\
\hline & & No & 578 & 58.03 & 850 & 64.54 \\
\hline \multirow[t]{4}{*}{ Exercise (hours per week) } & Total & & 995 & & 1325 & \\
\hline & & $0-4$ & 673 & 67.64 & 956 & 72.15 \\
\hline & & $5-10$ & 285 & 28.64 & 319 & 24.08 \\
\hline & & 11 or more & 37 & 3.72 & 50 & 3.77 \\
\hline \multirow[t]{5}{*}{ Quality of diet } & Total & & 992 & & 1309 & \\
\hline & & Poor & 148 & 14.92 & 223 & 17.04 \\
\hline & & Fair & 442 & 44.56 & 576 & 44.00 \\
\hline & & Good & 343 & 34.58 & 450 & 34.38 \\
\hline & & Excellent & 59 & 5.95 & 60 & 4.58 \\
\hline \multirow[t]{5}{*}{ Overall health quality } & Total & & 990 & & 1315 & \\
\hline & & Poor & 74 & 7.47 & 143 & 10.87 \\
\hline & & Fair & 365 & 36.87 & 534 & 40.61 \\
\hline & & Good & 434 & 43.84 & 550 & 41.83 \\
\hline & & Excellent & 117 & 11.82 & 88 & 6.69 \\
\hline \multirow[t]{4}{*}{ Mental health diagnosis } & Total & & 997 & & 1310 & \\
\hline & & Yes & 188 & 18.86 & 246 & 18.78 \\
\hline & & No & 751 & 75.33 & 1007 & 76.87 \\
\hline & & Prefer not to say & 58 & 5.82 & 57 & 4.35 \\
\hline
\end{tabular}

Note. Some percentages in this table do not add to $100 \%$ for a given variable because participants were able to respond with more than one option, or options with very low response rates $(<1 \%)$ were not listed here.

Note. First generation indicates student is the first in their family to attend post-secondary education. 
Overall, the samples provided a good representation of the diversity in the student population at McMaster University (see McMaster University Fact Book 2015-2016 for comparison), however, there were some exceptions to this. For example, there was a moderate overrepresentation of females: $75 \%$ of respondents were female but only $54 \%$ of students are female. This ratio is consistent with research indicating that females are more likely than males to respond to online surveys (e.g., Sax, Gilmartin, \& Bryant, 2003; Underwood, Kim, \& Matier, 2000). There was also a substantial underrepresentation of first-year students: only $4 \%$ of respondents were first-year students. Possible reasons for this are discussed below.

Since only 247 participants completed both the pre-break and post-break survey, the majority of the data analysis was completed in a between-subjects format. Within-subjects analyses of the effects of the break showed the same overall patterns, and using the between-subjects data to analyze for effects of demographic variables on measures of stress afforded higher statistical power.

\section{Measures of Stress}

Stress was assessed before and after the week-long fall break using two tools. The Perceived Stress Survey (PSS; Cohen et al., 1983) assessed the level of stress that students were experiencing. The Undergraduate Stress Questionnaire (USQ; Crandall et al., 1992) measured the number of stressors (out of 83) that students were experiencing.

Stress measures in entire sample. Our main question was whether student stress levels changed in connection with the break. Two independent samples t-tests assessing changes from pre- to post-break revealed that although the number of stressors (USQ) was lower after the break than before, $t(2432)=2.10, p<.05$, perceived stress (PSS) was higher after the break, $t(1997)=-2.87, p<$.01. (Note that modified degrees of freedom were used in the PSS analysis to control for the violation of the assumption of homogeneity of variance.)

Stress measures by demographic groups. In addition to evaluating the effect of the fall break on stress levels collapsed across the entire sample, we were also interested in how stress levels vary according to demographic variables, and whether the stress reported by certain groups is influenced by the timing of the survey. Thus, we completed a series of factorial ANOVAs including time of survey (pre/post) with several key demographic variables (see Figures 1 and 2). Note that time was run as a between-subjects variable because only 247 participants completed the pre-break and post-break surveys. General patterns for these analyses are presented in Figures 1 and 2, and details surrounding mean differences are provided below.

For the purposes of these analyses, main effects of time are not reported, as they were assessed in the analysis of the stress measures in the entire sample (see above). Additionally, our analyses revealed only one significant interaction among these variables, so reports in this section focus only on main effects of each demographic variable, with one exception (see below).

In omnibus analyses that violated the assumption of homogeneity of variance, Welch's correction was used. Pairwise comparisons were completed using the Scheffé test because of unequal group sizes within each demographic variable. If groups had heterogeneous variance, analyses were instead completed with the Games-Howell correction, which corrects for heterogeneous variance between groups and allows for unequal group sizes (Pituch, Whittaker, \& Stevens, 2007). 


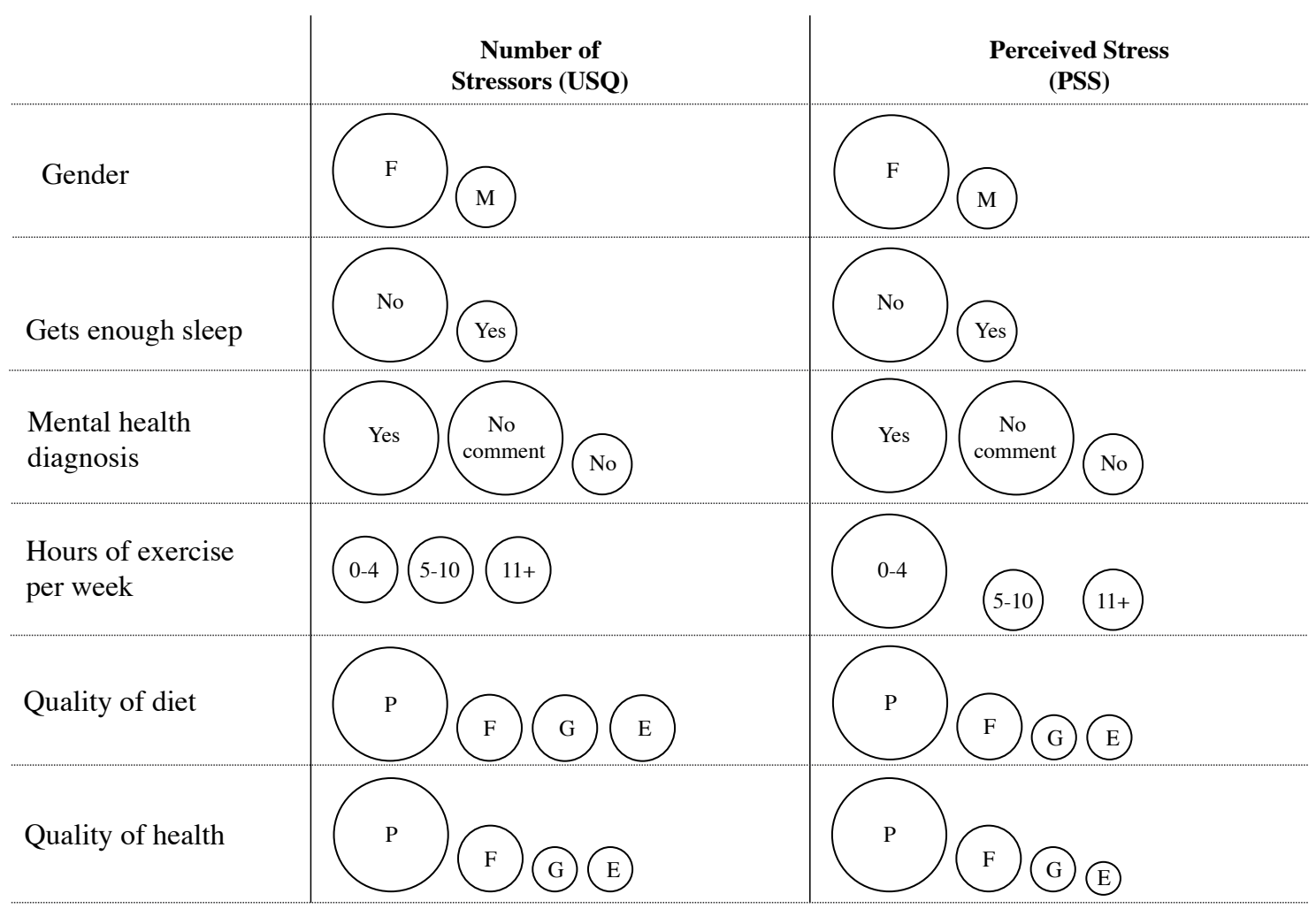

Note. $\mathrm{P}=$ poor, $\mathrm{F}=$ fair, $\mathrm{G}=$ good, $\mathrm{E}=$ excellent

Figure 1. Trends of stress scores by personal demographic variable. Larger bubbles indicate higher scores on stress questionnaire.

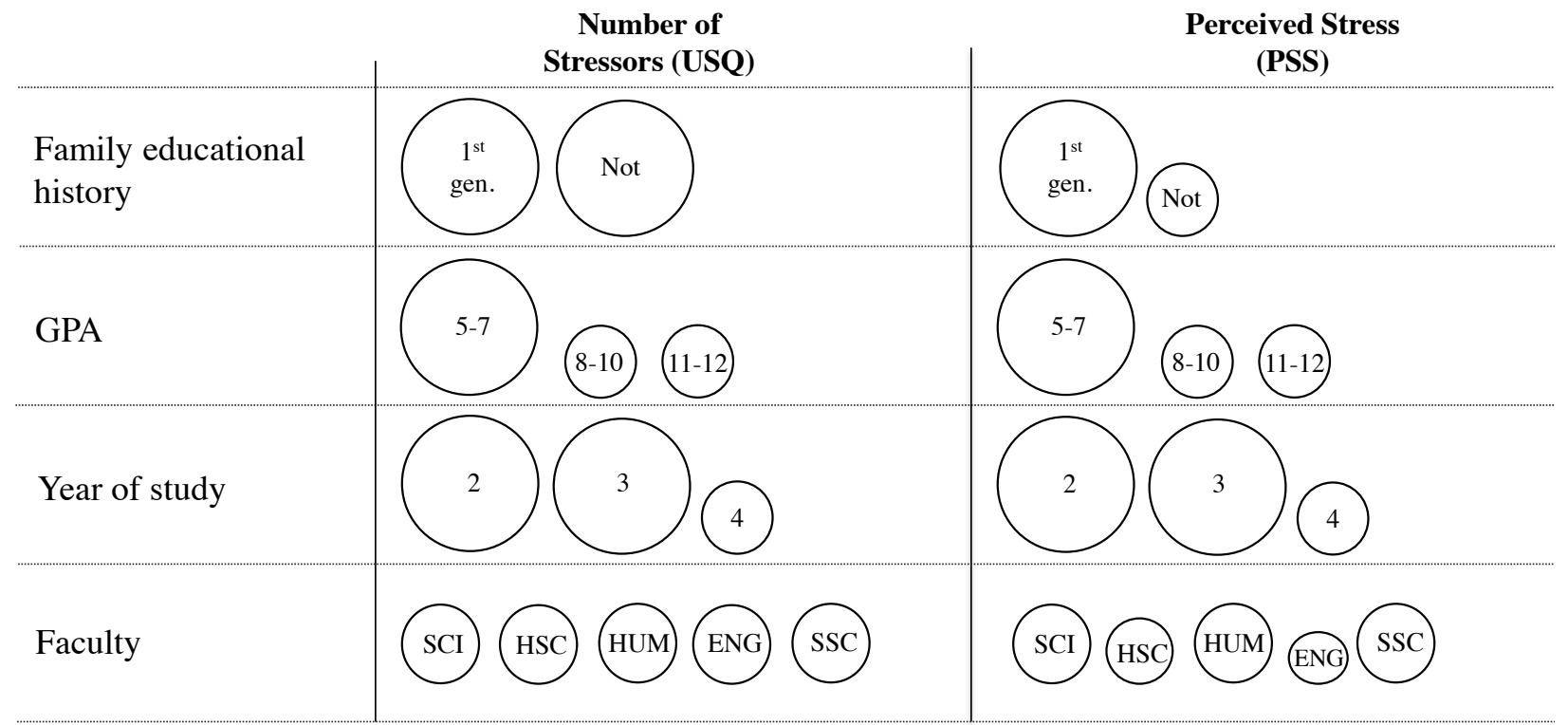

Note. $\mathrm{SCI}=$ Science, $\mathrm{HSC}=$ Health Sciences, $\mathrm{HUM}=$ Humanities, $\mathrm{ENG}=$ Engineering, $\mathrm{SSC}=$ Social Science

Figure 2. Trends of stress scores by academic demographic variable. Larger bubbles indicate higher scores on stress questionnaire. 
Gender. According to the USQ, females experienced significantly more stressors ( $M$ $=19.16)$ than males $(M=16.26, F(1,2282)=41.08, p<.001)$. Similarly, PSS scores indicated that females report higher perceived stress $(M=21.24)$ than males $(M=18.66$, $F(1,2254)=74.60, p<.001)$. Transgender respondents were excluded from these analyses due to small sample size $(n=12)$.

Family educational history. There was a significant main effect of generation status on PSS scores, such that perceptions of stress amongst first-generation students (those who are the first in their extended family to pursue post-secondary education) were significantly higher $(M=21.42)$ than those of students who were not first generation $(M=20.42, F(1,2327)=12.194, p<.001)$. There were no significant differences between these two groups on the USQ, $p \mathrm{~s}>.05$.

Year of study. Because less than $5 \%$ of respondents were in Years 1 and 5 , these students were excluded from the main analysis. Omnibus tests comparing USQ scores in Years 2, 3, and 4 students revealed a main effect of year of study, Welch's $F(2,1369)=$ $4.90, p<.01$. Post hoc comparisons using Games-Howell indicated that while second-year $(M=18.85)$ and third-year students $(M=19.04)$ did not differ in the number of stressors reported $(p>.90)$, both groups reported significantly more stressors than fourth-year students $(M=17.64, p s<.05)$.

PSS scores also varied by year of study, $F(2,2051)=5.16, p<.005$. Scheffé post hoc pairwise comparisons revealed that perceived stress amongst fourth-year students $(M=$ 19.91) was significantly lower than that of second-year students $(M=21.03$, mean difference $=1.115, p<.01)$, and third-year students $(M=20.95$, mean difference $=1.032, p=$ .01). No other differences were significant $(p>.90)$.

GPA. Students were asked to indicate their university GPA by placing it into one of four categories: $0-4(0 \%-62 \%), 5-7(63 \%-72 \%), 8-10$ (73\%-84\%), 11-12 (85\%-100\%). Since only $2 \%(n=48)$ of respondents fell into the lowest category, our omnibus analysis excluded this group. On USQ scores, there was a significant main effect of GPA, Welch's $F(2,971.37)=12.310, p<.001$. Games-Howell post hoc comparisons indicated that students with a GPA of $5-7$ reported significantly more stressors $(M=19.95)$ than students with a GPA of $8-10(M=18.05$, mean difference $=1.90, p<.005)$ or $11-12(M=17.02$, mean difference $=2.93, p<$.001). Students in the upper two categories of GPA did not significantly differ in terms of the number of stressors experienced, $p>.10$.

Analysis of PSS scores showed a significant main effect of GPA, Welch's $F(2,2112)$ $=17.88, p<.001$. Post hoc tests were completed using Games-Howell; this revealed that perceived stress amongst students with a GPA of $5-7(M=21.82)$ was significantly higher than that of students with a GPA of $8-10(M=20.00$, mean difference $=1.82, p<.001)$ and students with a GPA of $11-12(M=19.80$, mean difference $=2.03, p<.001)$. Differences in perceived stress between students in the two upper echelons of GPA were not significant, $p>.80$.

Faculty. Only a small portion of respondents indicated belonging to the Faculty of Business ( $n=137 ; 6 \%$ of respondents to this question, and only $5 \%$ of students in the faculty), so these individuals were excluded from the analysis. Subsequent analyses of USQ scores indicated a main effect of faculty, $F(4,2103)=2.38, p=.05$, however Scheffé post hoc tests indicated no significant differences in number of stressors between faculties, $p s>.07$. The largest difference between faculties was seen between students in the 
Faculty of Humanities $(M=19.63)$ and the Faculty of Engineering $(M=17.51)$. Note that the Scheffé test was used due to its ability to handle unequal group sizes (Klockars \& Hancock, 2000; McHugh, 2011) and because it thoroughly controls familywise error for the high number of comparisons being completed, but it is a conservative test with low statistical power (Howell, 2007).

Analyses of differences in PSS scores by faculty revealed the only significant interaction in the set of analyses. In addition to the main effect of faculty on PSS scores, $F(4,2077)=$ $5.26, p<.001$, there was also a significant interaction between faculty and time surveyed, $F(4,2077)=2.50, p<.05$. This interaction was further analyzed to establish the pattern of change in perceived stress around the fall break within each faculty. A series of independent t-tests using the Bonferroni procedure to hold familywise error at 0.05 indicated that perceived stress was significantly higher after the break than before the break among students in the Faculty of Science, $t(639)=-2.86, p=.004)$. Students in the other four faculties did not show a significant change in perceived stress (per comparison $p \mathrm{~s}>.01$ ).

Additionally, post hoc Scheffé analyses of the overall differences between faculties showed that students in the Faculty of Engineering reported significantly lower perceived stress than students in the Faculties of Social Science (mean difference $=1.72, p=.005$ ), Science (mean difference $=1.46, p=.009$ ) and Humanities (mean difference $=2.00, p=$ .002). No other differences were significant ( $p \mathrm{~s}>.05)$.

Mental health diagnosis. Nearly $19 \%$ of survey respondents reported receiving a mental health diagnosis (see Table 1), and there was a main effect of having a mental health diagnosis on USQ scores, $F(2,2294)=31.36, p<$.001. Post hoc Scheffé tests assessing pairwise differences indicated that those without a mental health diagnosis $(M=$ 17.58) reported significantly fewer stressors than those with a mental health diagnosis ( $M$ $=21.29, p<.001)$ or those who wished to not indicate the state of a diagnosis $(M=20.66$, $p<$.005). There was no significant difference between those who have a mental health diagnosis and those who did not wish to indicate whether they have one (mean difference = $0.63, p>.05$ ). There was also a main effect of mental health diagnosis on PSS scores. Post hoc comparison of means using the Scheffé test indicated that students without a mental health diagnosis $(M=19.87)$ were experiencing significantly less stress than students with a mental health diagnosis $(M=22.96, p<.001)$ or students who chose not to report their diagnostic status $(M=22.62, p<.001)$. Again, the difference between students who have been diagnosed and those who did not report their diagnostic status was not significant (mean difference $=0.34, p>.05$ ).

Overall health quality. There was a significant main effect of self-reported overall health on USQ scores, $F(3,2288)=71.62, p<.001$. Post hoc Scheffé analyses indicated that students with poor overall health reported significantly more stressors $(M=24.48)$ than students with fair overall health $(M=21.01$, Games-Howell $=4.17, p<.001)$, good overall health $(M=17.11$, Games-Howell $=8.22, p<.001)$, or excellent overall health $(M=14.57$, Games-Howell $=9.85, p<.001$ ). Furthermore, students with fair overall health reported more stressors than those with excellent overall health (Games-Howell $=5.68, p<.001$ ) and those with good overall health (Games-Howell $=4.04, p<.001$ ). The number of stressors reported by students with good overall health was not significantly different from that reported by students with excellent overall health (Games-Howell $=1.63, p>.05$ ). 
There was also a main effect of overall health quality on PSS scores, $F(3,2260)=$ $241.59, p<.001$. Once again, post hoc analyses revealed that perceived stress increased as self-reported health decreased. Specifically, students with poor overall health reported significantly higher perceived stress $(M=27.49)$ than students with fair overall health $(M=22.53$, Games-Howell $=4.96, p<.001)$, good overall health $(M=18.52$, GamesHowell $=8.97, p<.001)$, or excellent overall health $(M=15.31$, Games-Howell $=12.18$, $p<$.001). Furthermore, students with fair overall health reported higher perceived stress than those with excellent overall health (Games-Howell $=7.22, p<.001$ ) and those with good overall health (Games-Howell $=4.01, p<.001$ ). There was also significantly higher perceived stress amongst students with good overall health than those reporting excellent overall health (Games-Howell $=3.21, p<.001$ ).

Sleep. Students who said they do not sleep enough reported significantly more stressors $(M=20.13)$ than students who said they do sleep enough $(M=15.78)$, Welch's $F(1,2019)=124.79, p<.001$. Similarly, students who judged that they were not sleeping enough reported higher perceived stress $(M=21.77)$ than those who judged their sleep was sufficient $(M=18.79)$, Welch's $F(1,1788)=123.34, p<.001$.

Exercise. Students were asked to report whether they exercised o-4 hours per week, $5^{-10}$ hours per week, or 11 or more hours per week. Analyses of responses on this variable revealed a significant effect of exercise on USQ scores, $F(2,2309)=3.80, p<.025$. Post hoc Scheffé tests were not significant, but indicated the largest difference between students exercising least ( $0-4$ hours per week: $M=18.73$ ) and those exercising most (11 or more hours per week: $M=16.21, p=.057$ ).

Further analyses indicated a significant difference between exercise groups on perceived stress, $F(2,2283)=21.56, p<.001$. Post hoc Scheffé tests indicated that perceived stress was significantly higher in students who exercise $0-4$ hours per week $(M=21.15)$ than students who exercise $5-10$ hours per week $(M=19.51, p<.001)$ and those who exercise 11 or more hours per week $(M=18.13, p<$.001). No other differences were significant ( $p \mathrm{~s}>.15)$.

Diet quality. There was a significant main effect of self-reported diet quality on USQ scores, $F(3,2293)=17.96, p<.001$. Post hoc Scheffé analyses of this difference indicated that students with poor diet reported significantly more stressors $(M=21.54)$ than students with fair diet $(M=18.45, p<.001)$, good diet $(M=17.36, p<.001)$, or excellent diet ( $M=16.78, p<.001)$. No other groups differed significantly. There was also a main effect of diet quality on PSS scores, $F(3,2262)=71.77, p<.001$. Post hoc Scheffé analyses revealed that stress generally increased as diet worsened. Specifically, students with poor diet reported significantly higher perceived stress $(M=24.23)$ than students with fair $\operatorname{diet}(M=20.85, p<.001)$, good diet $(M=19.04, p<.001)$, or excellent diet $(M=17.57$, $p<$.001). Furthermore, students with fair diet reported higher perceived stress than those with good diet $(p<.001)$ and those with excellent diet $(p<.001)$. There was no significant difference in perceived stress amongst students with good diet and those with excellent $\operatorname{diet}(p=.117)$.

\section{January Survey}

Frequency analyses indicated general satisfaction with the fall break: in a forced choice question asking whether the fall break was "a good thing" for them, $80 \%$ of respondents 
indicated the affirmative and only $20 \%$ of respondents indicated the negative. Students were also asked to assess the effect of the fall break on their stress levels over the entire fall semester. The majority (69\%) of respondents indicated that the fall break decreased stress. However, it is relevant to note that a substantial portion (18\%) of students reported that it increased stress over the course of the semester. Evaluations of the effect of the fall break on academic performance were generally positive, with $53 \%$ of respondents indicating that it improved their academic performance, and less than $10 \%$ indicating a detriment to academic performance (Figure 3). One possibility with the fall break was that it would lead to an initial decrease in stress, but would lead to a rebound in December, as the final exam period was compressed. However, $45 \%$ of respondents indicated that their exam period was uninfluenced by the fall break (no change in busy-ness), and only $14 \%$ indicated that the exam period was much more busy. Finally, students were asked to indicate when they would best like the fall break to be held. This analysis indicated some discontent with the current schedule: while $41 \%$ of respondents indicated that the fall break should be held in the same time as it was that year (October 12-16, 2015), 35\% indicated that they would prefer it be held in November, and $16 \%$ would prefer it be held immediately before December exams. Additionally, $8 \%$ of respondents indicated that they would prefer the fall break not be held at all.

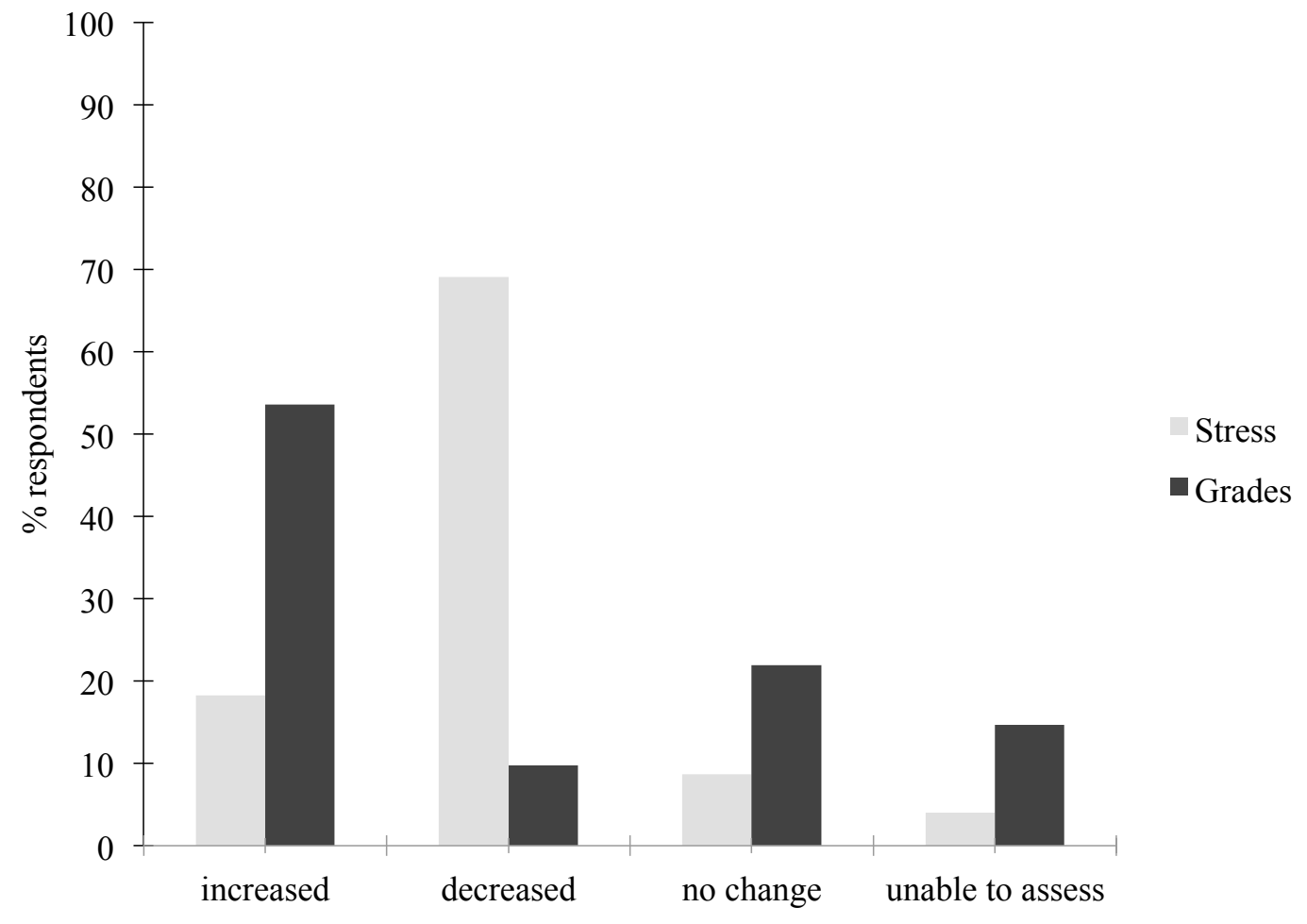

Figure 3. Self-reported impact of the fall break over the entire fall semester provided retrospectively in January.

Note. Sixty-nine percent of respondents indicated that the fall break decreased stress, whereas $18 \%$ reported that it increased stress over the course of the fall semester. Evaluations of the impact of the fall break on academic performance were generally positive, with $53 \%$ of respondents indicating that it improved their academic performance, and less than $10 \%$ indicating a detriment to academic performance. 


\section{Discussion}

Despite the widespread suggestion that a fall break will decrease student stress and support student mental health (e.g., Campbell, 2015; Cramer \& Pschibul, 2017; CBC Saskatoon, 2014; Elworthy, 2014; Grewal, 2017; Harvey \& McGuire, 2012; Irish, 2013; McMaster Daily News, 2015; University of Lethbridge, 2015; University of Winnipeg, 2015; Weber, 2012), our work indicates that the effects of this intervention are by no means simple or straightforward. Responses from a large sample of students at McMaster University on two validated and standardized measures of stress revealed that although students reported experiencing fewer life event stressors after the break than before it, they experienced higher levels of overall stress. In addition, stress varied according to several demographic variables, revealing some groups to be at higher risk than others for stressrelated problems. For example, female students reported more stress than their male counterparts, first-generation students manifested more stress relative to students from families with members who have attended post-secondary institutions, and students with a lower university GPA reported more stress than those with higher grades. Nonetheless, in a follow-up survey at the start of the winter term, students overwhelmingly supported the idea of a fall break and indicated that it decreased their stress across the fall term.

The complex link between a fall break and student stress is consistent with research on the relationship between stress and vacations in non-student samples. Although stress usually drops during vacation, it often increases to pre-vacation levels once an individual resumes work. For example, some studies have found that employees' self-reported levels of stress were lower immediately after a vacation than before it (Etzion, 2003; Westman \& Etzion, 2001), but had rebounded to original levels within days (Westman \& Eden, 1997) or weeks (Etzion, 2003; Westman \& Etzion, 2001) of returning to work. Furthermore, a heavy workload upon the return to work can substantially attenuate the stress benefits of a vacation (Strauss-Blasche, Ekmekcioglu, \& Marktl, 2002), and increases in happiness after a vacation are only likely if the vacation is extremely relaxing (Nawijn, Marchand, Veenhoven, \& Vingerhoets, 2010). This may be particularly relevant in the context of the fall break our participants experienced, since many of them commented in our followup survey that the shortened semester led to a particularly dense schedule of midterm exams and assignments immediately after the fall break. If students spent much of their fall break worrying about and preparing for a busy upcoming week of exams (instead of relaxing), they may not have benefitted from the time off, at least from the perspective of stress-reduction. While our survey did not document how students spent their time during the fall break, in a separate study, we asked students to track their activities periodically over the break via a text-messaging response system. We plan to assess the link between break-behaviour and stress in an upcoming publication (Poole \& Khan, 2018).

When we examined students' responses collapsing across time (pre- vs. post-break), a general pattern emerged supporting the popular consensus that a healthy lifestyle is associated with positive mental health. That is, if a student's routine included any single variable associated with a healthy lifestyle (such as a healthy diet, regular exercise, or sufficient sleep), the reported stress was lower. This was generally true for both measures of stress (number of stressors and perceived stress).

Based on research indicating that first-year students are particularly prone to stress due to the transitional nature of their life-stage (D'Zurilla \& Sheedy, 1991; Towbes \& Co- 
hen, 1996), we were particularly interested in assessing the effect of the fall break on this group. Unfortunately, we excluded first-year students from our analyses because they were severely under-represented in the sample (only $4 \%$ of respondents were first-year students). While we are unable to provide a definite explanation for this low response rate, one possible reason is that first-year students do not yet habitually check their university emails, and thus did not receive the email link to the survey. Considering literature suggesting that first-year students prefer text messaging (SMS) to email (see Harley, Winn, Pemberton, \& Wilcox, 2007) and the fact that our surveys were emailed early in the fall semester, slow adjustment to the university email system seems a plausible factor in the low response rate of this group. Another possibility is that the research question was not particularly relevant to first-year students; unlike upper-year students they have not experienced a fall semester with a shorter or non-existent fall break. Future research could benefit from more active or novel methods for recruitment of first-year students.

In spite of the absence of first-year students in the analysis, we found that students in their fourth year of study experienced less stress and reported fewer daily stressors than students in earlier years. In comparison to their under-year peers, fourth-year students might have more strategies and more developed social support networks to cope with stress (Mishra, McKean, West, \& Russo, 2000); they may also have fewer midterm exams due to the nature of upper-year courses, which often have a major term project instead of numerous smaller assessments. Further research could compare coping mechanisms between junior and senior students, or could follow students longitudinally to see how coping skills change throughout university. Such research could inform universities as they develop programs and interventions to support students.

While it is beneficial to experience a moderate level of arousal for optimal performance (Yerkes \& Dodson, 1908), chronic stress can impair a variety of health outcomes (McEwen, 1998). Prolonged stressful life events have been shown to correlate with illness (Li \& Lin, 2003; Segerstrom \& Miller, 2004). Consistent with this, in our sample, we observed a predictable pattern of student responses in relation to their self-reported health status. Those that reported excellent health also had the lowest levels of stress while those that perceived their health as poor showed the highest stress. Persistently high levels of stress are also linked with decreased mental health (McLaughlin et al., 2010; McMahon, Grant, Compas, Thurm, \& Ey, 2003). A substantial proportion of our sample (almost 19\%) reported having a mental health diagnosis. While the fall break is designed to help all students manage stress, one might expect that it is most important to reach those students who already have an increased susceptibility to stress. However, our results indicate that the fall break might not be effective at this: students with mental health diagnoses reported higher levels of stress than the rest of the sample, and this division was not decreased due to the fall break. This is particularly troubling, as the fall break is designed to decrease stress, and this is especially important for students who are already at a disadvantage for managing stress, as we might expect among those with a mental health diagnosis.

Furthermore, many students experience serious stress-related health problems without seeking treatment (Emory University, 2005). Since depression and anxiety disorders are common in university undergraduates, and indeed often emerge in late adolescence (Merikangas, 2005), it is imperative that mental health strategies touted by universities are effective at supporting students' mental health. An additional barrier to treatment could 
be availability of services. While universities habitually provide mental health centres, wait list times are often very long (Arnold, Isai, \& Raskina, 2015; Lunau, 2012; Thielking, 2017). Students may become discouraged or reach a crisis before they are able to access services (Feinstein, 2013); more effective campus strategies to decrease stress could prevent this and shorten wait lists. Regardless, our findings indicate that students with a mental health diagnosis may not be adequately supported by the simple introduction of a fall break.

One limitation of our study was the manner in which stress was assessed. Firstly, we did not assess stress levels during the actual break period. As discussed above, it is possible that stress levels decreased during the break but rebounded upon students' return, consistent with literature on stress and vacations (Westman \& Eden, 1997). Such a pattern could explain the students' overall positive perceptions of the effect of the fall break collected in January. Our present approach did not allow us to assess stress during the break itself, but this may be a worthwhile approach to include in future studies. Secondly, all of the data discussed above derive from the respondents' self-reports. As such, the validity of these measures may be limited, for example, by inconsistent interpretations of valence statements (e.g., what constitutes "good" health), socially desirable responses (e.g., over-reporting frequency of exercise), or failures in memory. We have developed a protocol that may allow for validation of self-reported stress through tracking physiological correlates of stress (Khan, Poole, \& Beaton, 2018).

We suspect that the timing of the fall break as well as the name itself might create some confusion amongst students and instructors about how the break should be used. If students, instructors, and university staff have different conceptions of the purpose of the fall break, there will be variation in how students choose to use their time, whether instructors are scheduling course deadlines before or after the break, and the amount of co-curricular programming that university departments offer to undergraduate students. It might be worthwhile for institutions to consider a global test ban one to two days before and particularly after the break to allow students to transition into their regular routines. It might also be worth considering scheduling the break later in the term so that most of the tests and assignments have been completed.

Given the increasing adoption of fall breaks as a strategy for reducing student stress, it is critical to examine their efficacy. Through our work we hope to initiate dialogue about the importance of evidence-based decisions in the development of stress-reduction interventions to support student health and well-being.

\section{Acknowledgements}

This research was supported by grants from the Canadian Association of College and University Student Services (CACUSS) and the McMaster University Arts Research Board. We greatly appreciate the contributions of Jeremy Sandor, Nathan Cooper, Sean Beaudette, Arpa Modi, Bismah Basharat, Joshua Wiener, Irina Ghilic, and Amanda Stypulkowski.

\section{References}

Adlaf, E. M., Gliksman, L., Demers, A., \& Newton-Taylor, B. (2001). The prevalence of elevated psychological distress among Canadian undergraduates: Findings from the 1998 Canadian Campus Survey. Journal of American College Health, 5o(2), 67-72. 
Aherne, D. (2001). Understanding student stress: A qualitative approach. The Irish Journal of Psychology, 22(3-4), 176-187.

American College Health Association (2016). ACHA - National College Health Assessment II: Canadian reference group executive summary. Hanover, MD:

American College Health Association. Retrieved from https://tinyurl.com/y8ox838c

Archer, J., Jr., \& Lamnin, A. (1985). An investigation of personal and academic stressors on college campuses. Journal of College Student Personnel, 26(3), 210-215.

Arnett, J. J. (1994). Are college students adults? Their conceptions of the transition to adulthood. Journal of Adult Development, 1(4), 213-224.

Arnold, C., Isai, V., \& Raskina, K. (2015, December 2). Mental health report: Students who need help left waiting for counselling services. Ryersonian. Retrieved from http:// ryersonian.ca/students-who-need-help-left-waiting-for-counselling-services/

Bartlett, V. (2014). A roadmap for federal action on student mental health. The Canadian Alliance of Student Associations. Retrieved from https://d3n8a8pro7vhmx. cloudfront.net/casaacae/pages/811/attachments/original/1463347855/CASA-ARoadmap-for-Federal-Action-on-Student-Mental-Health.pdf? 1463347855

Beiter, R., Nash, R., McCrady, M., Rhoades, D., Linscomb, M., Clarahan, M., \& Sammut, S. (2015). The prevalence and correlates of depression, anxiety, and stress in a sample of college students. Journal of Affective Disorders, 173, 90-96.

Booth, R. W., Sharma, D., \& Leader, T. I. (2016). The age of anxiety? It depends where you look: Changes in STAI trait anxiety, 1970-2010. Social Psychiatry and Psychiatric Epidemiology, 51(2), 193-202.

Campbell, M. (2015, November 19). How to fight the mental health crisis on campus: Fall breaks. Maclean's Magazine. Retrieved from http://www.macleans.ca/education/ how-to-fight-the-mental-health-crisis-on-campus-fall-breaks/

Canadian Alliance of Student Associations. (2017, August). "Shared perspectives": A joint publication on student mental health. Retrieved from https://d3n8a8pro7vhmx. cloudfront.net/ousa/pages/464/attachments/original/1501593637/Shared_ Perspectives_Joint_Publication_on_Student_Mental_Health_document. pdf?1501593637

Canadian Mental Health Association. (n.d.). Mental health for all. Retrieved from http://getloud.mentalhealthweek.ca/

Casey, L. (2017, March 26). Guelph University execs check door-to-door on student mental health. CBC News. Retrieved from http://www.cbc.ca/news/canada/kitchenerwaterloo/university-guelph-suicide-door-check-student-mental-health-francovaccarino-1.4041687

CBC Saskatoon. (2014, February 19). University of Saskatchewan students will get fall break.

CBC News. Retrieved from http://www.cbc.ca/news/canada/saskatoon/universityof-saskatchewan-students-will-get-fall-break-1.2543030 
Centre for Innovation in Campus Mental Health. (n.d.). Helping Ontario's colleges and universities enhance capacity to support student mental health and well-being. Retrieved from http://campusmentalhealth.ca/

Chiose, S. (2016, September 8). Reports of mental health issues rising among postsecondary students: Study. The Globe \& Mail. Retrieved from http://www. theglobeandmail.com/news/national/education/reports-of-mental-health-issuesrising-among-postsecondary-students-study/article31782301/

Cohen, S., Kamarck, T., \& Mermelstein, R. (1983). A global measure of perceived stress. Journal of Health and Social Behavior, 24(4), 385-396.

COPE McMaster. (n.d.). A student mental health initiative. Retrieved from http:// copex.weebly.com/

Crandall, C. S., Preisler, J. J., \& Aussprung, J. (1992). Measuring life event stress in the lives of college students: The Undergraduate Stress Questionnaire (USQ). Journal of Behavioral Medicine, 15(6), 627-662.

Cramer, K., \& Pschibul, R. (2017). Student time usage during fall reading week. Collected Essays on Learning and Teaching, 10, 155-162.

Deliens, T., Clarys, P., De Bourdeaudhuij, I., \& Deforche, B. (2014). Determinants of eating behaviour in university students: A qualitative study using focus group discussions. BMC Public Health, 14(1), 53.

Dill, P. L., \& Henley, T. B. (1998). Stressors of college: A comparison of traditional and nontraditional students. The Journal of Psychology, 132(1), 25-32.

Durand-Bush, N., McNeill, K., Harding, M., \& Dobransky, J. (2015). Investigating stress, psychological well-being, mental health functioning, and self-regulation capacity among university undergraduate students: Is this population optimally functioning?/Une étude des niveaux de stress, bien-être psychologique, santé mentale, et capacité d'autorégulation chez les étudiants universitaires de premier cycle: Cette population fonctionnet-elle de façon optimale? Canadian Journal of Counselling and Psychotherapy (Online), 49(3), 253-274.

D’Zurilla, T. J., \& Sheedy, C. F. (1991). Relation between social problem-solving ability and subsequent level of psychological stress in college students. Journal of Personality and Social Psychology, 61(5), 841-846.

Eisenberg, D., Gollust, S. E., Golberstein, E., \& Hefner, J. L. (2007). Prevalence and correlates of depression, anxiety, and suicidality among university students. American Journal of Orthopsychiatry, 77(4), 534-542.

Elmquist, J. K., Bjorbaek, C., Ahiman, R. S., Flier, J. S., \& Saper, C. B. (1998). Distribution of leptin receptor mRNA isoforms in the rat brain. The Journal of Comparative Neurology, 395(4), 535-547.

Elworthy, C. (2014, February 27). Fall reading week campaign highlights student stress. The Ontarion. Retrieved from https://www.theontarion.com/2014/o2/fallreading-week-campaign-highlights-student-stress/

Emory University. (2005, December). Mental health task force report. Retrieved from http://studenthealth.emory.edu/cs/documents/taskforce.pdf 
Etzion, D. (2003). Annual vacation: Duration of relief from job stressors and burnout. Anxiety, Stress, and Coping, 16(2), 213-226.

Feinstein, S. (2013, September 24). I dropped out of McGill because of depression. Maclean's Magazine. Retrieved from http://www.macleans.ca/education/uniandcollege/ i-dropped-out-of-mcgill-because-of-depression/

Gerdes, H., \& Mallinckrodt, B. (1994). Emotional, social, and academic adjustment of college students: A longitudinal study of retention. Journal of Counseling \& Development, 72(3), 281-288.

Ginsberg, J., \& Gapen, M. (2007). Academic worry as a predictor of sleep disturbance in college students. Journal of Young Investigators, 14(4).

Good2Talk. (n.d.). Post-secondary student helpline. Retrieved from http://www. good2talk.ca/

Grewal, I. (2017, March 8). Why U of G students need a reading week in the fall semester. The Ontarion. Retrieved from https://www.theontarion.com/2017/o3/why-uof-g-students-need-a-reading-week-in-the-fall-semester/

Haleem, D. J., Haider, S., Perveen, T., \& Haleem, M. A. (2015). Serum leptin and cortisol, related to acutely perceived academic examination stress and performance in female university students. Applied Psychophysiology and Biofeedback, 4O (4), 305-312.

Harley, D., Winn, S., Pemberton, S., \& Wilcox, P. (2007). Using texting to support students' transition to university. Innovations in Education and Teaching International, 44(3), 229-241.

Harvey, C., \& McGuire, A. (2012, October). Fall reading break. Retrieved from http:// westernusc.ca/wp-content/uploads/2014/o6/Purple-Paper-Fall-Reading-Break.pdf

Healthy Minds at UBC. (n.d.). Live well, feel good, achieve success. Retrieved from https://students.ubc.ca/health/take-care-mind-body-spirit

Hicks, R. A., \& Garcia, E. R. (1987). Level of stress and sleep duration. Perceptual and Motor Skills, 64(1), 44-46.

Holahan, C. J., Valentiner, D. P., \& Moos, R. H. (1994). Parental support and psychological adjustment during the transition to young adulthood in a college sample. Journal of Family Psychology, 8(2), 215-223.

Howell, D. C. (2007). Statistical methods for psychology. Belmont, CA: Thomson Wadsworth.

Hudd, S. S., Dumlao, J., Erdmann-Sager, D., Murray, D., Phan, E., Soukas, N., \& Yokozuka, N. (2000). Stress at college: Effects on health habits, health status and selfesteem. College Student Journal, 34(2), 217-228.

Hurst, C. S., Baranik, L. E., \& Daniel, F. (2013). College student stressors: A review of the qualitative research. Stress and Health, 29(4), 275-285.

Ibrahim, A. K., Kelly, S. J., Adams, C. E., \& Glazebrook, C. (2013). A systematic review of studies of depression prevalence in university students. Journal of Psychiatric Research, 47(3), 391-400. 
Irish, P. (2013, October 14). Ontario universities embrace mid-term "fall break" to ease students' minds. The Toronto Star. Retrieved from https://www.thestar.com/life/ health_wellness/2013/10/14/ontario_universities_embrace_midterm_fall_break_to_ ease_students_minds.html

Jack.org. (n.d.). Mental health awareness. Retrieved from https://www.jack.org/

Jow, G. M., Yang, T. T., \& Chen, C. L. (2006). Leptin and cholesterol levels are low in major depressive disorder, but high in schizophrenia. Journal of Affective Disorders, 9o(1), 21-27.

Kelly, W. E., Kelly, K. E., \& Clanton, R. C. (2001). The relationship between sleep length and grade-point average among college students. College Student Journal, 35(1), 84-86.

Khan, A., Poole, H., \& Beaton, E. A. (2018). Measuring the impact of a weeklong fall break on stress physiology in first year engineering students. The Canadian Journal for the Scholarship of Teaching and Learning, 9(2).

Kirnishni, T. (2014, December 2). Fall breaks here to stay on more Ontario university campuses. Carleton YPolitics. Retrieved from http://cusjc.ca/ypolitics/fall-breaks-hereto-stay-on-more-ontario-university-campuses/

Kitzrow, M. A. (2003). The mental health needs of today's college students: Challenges and recommendations. NASPA Journal, 41(1), 167-181.

Klainin-Yobas, P., Keawkerd, O., Pumpuang, W., Thunyadee, C., Thanoi, W., \& He, H.G. (2014). The mediating effects of coping on the stress and health relationships among nursing students: A structural equation modelling approach. Journal of Advanced Nursing, $70(6), 1287-1298$.

Klockars, A. J., \& Hancock, G. R. (2000). Scheffé's more powerful F-protected post hoc procedure. Journal of Educational and Behavioral Statistics, 25(1), 13-19.

Lewin, T. (2011, January 26). Record level of stress found in college freshmen. The New York Times. Retrieved from http://www.nytimes.com/2011/01/27/education/27colleges. html

Li, H., \& Lin, C. (2003). College stress and psychological well-being of Chinese college students. Acta Psychologica Sinica, 35(2), 222-230.

Loss, S. (1997). Sleep loss results in an elevation of cortisol levels the next evening. Sleep, 20(10), 865-870.

Lunau, K. (2012, September 5). The mental health crisis on campus. Maclean's. Retrieved from http://www.macleans.ca/education/uniandcollege/the-mental-healthcrisis-on-campus/

Lund, H. G., Reider, B. D., Whiting, A. B., \& Prichard, J. R. (2010). Sleep patterns and predictors of disturbed sleep in a large population of college students. Journal of Adolescent Health, 46(2), 124-132.

McEwen, B. S. (1998). Stress, adaptation, and disease: Allostasis and allostatic load. Annals of the New York Academy of Sciences, 840(1), 33-44. 
McHugh, M. L. (2011). Multiple comparison analysis testing in ANOVA. Biochemia Medica, 21(3), 203-209.

McLaughlin, K. A., Green, J. G., Gruber, M. J., Sampson, N. A., Zaslavsky, A. M., \&

Kessler, R. C. (2010). Childhood adversities and adult psychopathology in the National Comorbidity Survey Replication (NCS-R) III: Associations with functional impairment related to DSM-IV disorders. Psychological Medicine, 4O(5), 847-859.

McMahon, S. D., Grant, K. E., Compas, B. E., Thurm, A. E., \& Ey, S. (2003). Stress and psychopathology in children and adolescents: Is there evidence of specificity? Journal of Child Psychology and Psychiatry, 44(1), 107-133.

McMaster Daily News. (2015, January 15). McMaster approves full week fall break. McMaster Daily News. Retrieved from http://dailynews.mcmaster.ca/article/mcmasterapproves-full-week-fall-break/

McMaster University Fact Book, 2015-2016. (2016). Retrieved from http://www. mcmaster.ca/vpacademic/documents/FactBook2015-2016.pdf

Merikangas, K. R. (2005). Vulnerability factors for anxiety disorders in children and adolescents. Child and Adolescent Psychiatric Clinics of North America, 14(4), 649-679.

Mishra, R., McKean, M., West, S., \& Russo, T. (2000). Academic stress of college students: Comparison of student and faculty perceptions. College Student Journal, 34(2), 236-246.

Nawijn, J., Marchand, M. A., Veenhoven, R., \& Vingerhoets, A. (2010). Vacationers happier, but most not happier after a holiday. Applied Research in Quality of Life, 5(1), $35-47$.

OUSA. (2017, May 3). Students celebrate government investment into increased mental health supports on campuses across Ontario. Ontario Undergraduate Student Alliance. Retrieved from http://www.ousa.ca/newsroom_mental_health_supports

Pituch, K. A., Whittaker, T. A., \& Stevens, J. P. (2007). Intermediate statistics: A modern approach (3rd ed.). New York, NY: Taylor \& Francis.

Pilato, K. (2014). Exploring the impact of a Fall Break on student mental health outcomes: Year 1 Report. Report submitted to Vice-Provost and Associate Vice-President (Student Services), Brock University. Retrieved from https://brocku.ca/webfm _ send/33279

Poole, H., \& Khan, A. (2018). Text messaging study. Article in preparation.

Poole, H., Khan, A., \& Agnew, M. (2017). One week, many ripples: Measuring the impacts of the fall reading week on student stress. Collected Essays on Learning and Teaching, 10(7), 163-172.

Poyrazli, S., \& Lopez, M. D. (2007). An exploratory study of perceived discrimination and homesickness: A comparison of international students and American students. The Journal of Psychology, 141(3), 263-280. 
Queen's Gazette. (2017, August 8). 'Green Folder' initiative promotes mental health, resources. Queen's Gazette. Retrieved from http://www.queensu.ca/studentwellness/ sites/webpublish.queensu.ca.swswww/files/files/MentalHealth/Green\%2ofolder\%20 Aug\%202014.pdf

Rao, U. M. A., Hammen, C., \& Daley, S. E. (1999). Continuity of depression during the transition to adulthood: A 5-year longitudinal study of young women. Journal of the American Academy of Child \& Adolescent Psychiatry, 38(7), 908-915.

Sapolsky, R. M. (1994). Why zebras don't get ulcers: A guide to stress, stress- related diseases, and coping. New York, NY: Holt Paperbacks.

Sax, L. J., Gilmartin, S. K., \& Bryant, A. N. (2003). Assessing response rates and nonresponse bias in web and paper surveys. Research in Higher Education, 44(4), 409432.

Scelfo, J. (2016, July 27). Suicide on campus and the pressure of perfection. The New York Times. Retrieved from https://www.nytimes.com/2015/08/02/education/edlife/ stress-social-media-and-suicide-on-campus.html

Segerstrom, S. C., \& Miller, G. E. (2004). Psychological stress and the human immune system: A meta-analytic study of 30 years of inquiry. Psychological Bulletin, 13O(4), 601630.

Smith, J. (2016, March 2). Student mental health. A new model for universities. The Guardian. Retrieved from https://www.theguardian.com/higher-education-network/ 2016/mar/02/student-mental-health-a-new-model-for-universities

Stallman, H. M. (2010). Psychological distress in university students: A comparison with general population data. Australian Psychologist, 45(4), 249-257.

Strauss-Blasche, G., Ekmekcioglu, C., \& Marktl, W. (2002) Moderating effects of vacation on reactions to work and domestic stress. Leisure Sciences, 24(2), 237-249.

Stuart, M., Lido, C., Morgan, J., Solomon, L., \& May, S. (2011). The impact of engagement with extracurricular activities on the student experience and graduate outcomes for widening participation populations. Active Learning in Higher Education, 12(3), 203-215.

Thielking, M. (2017, February 6). A dangerous wait: Colleges can't meet soaring student needs for mental health care. Stat News. Retrieved from https://www. statnews.com/2017/02/06/mental-health-college-students/?s_campaign=fb\&utm_ content $=$ buffera7144\&utm_medium =social\&utm_source=facebook.com\&utm _ campaign $=$ buffer

Towbes, L. C., \& Cohen, L. H. (1996). Chronic stress in the lives of college students: Scale development and prospective prediction of distress. Journal of Youth and Adolescence, 25(2), 199-217.

Underwood, D., Kim, H., \& Matier, M. (2000, May). To mail or to web: Comparisons of survey response rates and respondent characteristics. Paper presented at the 40th Annual Forum of the Association for Institutional Research, Cincinnati, OH.

University of British Columbia. (2017). 2017-2018 University of British Columbia 
catalog. Retrievedfromhttp://www.calendar.ubc.ca/okanagan/courses.cfm?code=HEAL

University of Lethbridge. (2015, December 15). Fall reading break approved for 2016. University of Lethbridge UNews. Retrieved from https://www.uleth.ca/unews/article/ fall-reading-break-approved-2016\#.

University of Manitoba. (2014). Success through wellness: Enhancing the campus community to promote and support mental health and well-being. Retrieved from http:// umanitoba.ca/student/media/U_of_M_Campus_Mental_Health_Strategy_-_full.pdf

University of Waterloo. (n.d.). Fall break. Retrieved from https://uwaterloo.ca/ student-success/fall-break

University of Winnipeg. (2015, May 5). UWinnipeg to introduce fall reading week. University of Winnipeg NewsCentre. Retrieved from http://news-centre.uwinnipeg.ca/ all-posts/uwinnipeg-to-introduce-fall-reading-week/

Walker, D., Tierney, A., Clapham, L., Medves, J., \& Jahchan, R. (2012). Student mental health and wellness: Framework and recommendations for a comprehensive strategy. Retrieved from http://www.queensu.ca/principal/sites/webpublish.queensu. ca.opvcwww/files/files/CMHFinalReport.pdf

Warner, L. (2016, February 17). It's not enough to just talk about mental health. Times Higher Education. Retrieved from https://www.timeshighereducation.com/student/ advice/student-blog-its-not-enough-just-talk-about-mental-health

Weber, A. (2012, November 21). Another study break for Western University students. The London Free Press. Retrieved from http://www.lfpress.com/2012/11/20/stresscited-for-long-weekend

Westman, M., \& Eden, D. (1997). Effects of a respite from work on burnout: Vacation relief and fade-out. Journal of Applied Psychology, 82(4), 516-527.

Westman, M., \& Etzion, D. (2001). The impact of vacation and job stress on burnout and absenteeism. Psychology \& Health, 16(5), 595-606.

Yerkes, R. M., \& Dodson, J. D. (1908). The relation of strength of stimulus to rapidity of habit-formation. Journal of Comparative Neurology, 18(5), 459-482.

\section{Contact Information}

Heather Poole

University of Ottawa

School of Psychology

hpoole@uottawa.ca

Dr. Heather Poole is a teaching professor in the School of Psychology at the University of Ottawa. She has a background in cognitive psychology, which she uses to inform her teaching and her research in SoTL. She is a founding member of a multi-institutional research team studying the effects of university policies on student stress and mental health.

Dr. Ayesha Khan is a teaching stream assistant professor in the Faculty of Science at Mc- 
Master University. She holds a fellowship at the MacPherson Institute for Leadership, Innovation \& Excellence in Teaching at McMaster, and is the recent recipient of the President's Award for Outstanding Contributions to Teaching \& Learning. As part of a multi-institutional Canadian initiative, her current research interests include studying the effect of undergraduate-focused university policies on the mental health of post-secondary students.

Michael Agnew is a postdoctoral research fellow at the MacPherson Institute for Leadership, Innovation and Excellence in Teaching at McMaster University in Hamilton, Ontario. 